Maria Teresa Costa and Hans Christian Hönes (eds)

\title{
MIGRATING HISTORIES OF ART
}

Self-Translations of a Discipline 
STUDIEN AUS DEM WARBURG-HAUS, BAND 19

Herausgegeben von

Uwe Fleckner

Margit Kern

Birgit Recki

Cornelia Zumbusch 
Maria Teresa Costa and Hans Christian Hönes (eds)

\section{MIGRATING HISTORIES OF ART}

Self-Translations of a Discipline

\section{DE GRUYTER}


